\title{
Evaluation of spot patterns and carapace abnormalities of an Endangered freshwater turtle, Clemmys guttata, as a potential tool for population assignment
}

\author{
Lucille J. Brown ${ }^{1}$, Christina M. Davy ${ }^{1,2, *}$ \\ ${ }^{1}$ Wildlife Research and Monitoring Section, Ontario Ministry of Natural Resources and Forestry, Trent University, \\ Peterborough, Ontario K9L 0G2, Canada \\ ${ }^{2}$ Department of Biology, Trent University, Peterborough, Ontario K9L 0G2, Canada
}

\begin{abstract}
Many of the world's contemporary species of turtle are extinct or threatened with extinction due to habitat loss, increases in anthropogenic sources of mortality, and poaching (illegal collection). The slow life-history strategy of most turtle species magnifies the effects of poaching because the loss of even a few mature individuals can impact population growth. Returning poached turtles to their population of origin, where possible, can mitigate these effects, but identifying the origin of these individuals can be challenging. We hypothesized that spot patterns might allow assignment of Endangered spotted turtles Clemmys guttata to their population of origin. We characterized and compared spot patterns from carapace photographs of 126 individuals from 10 sites. To explore other types of information these photographs might provide, we also documented carapacial scute abnormalities and quantified their association with genetic diversity and latitude. Spot pattern similarity was not higher within populations than among populations and did not accurately differentiate populations. Carapacial scute abnormalities occurred in $82 \%$ of turtles and were not correlated with estimates of neutral genetic diversity. Abnormalities were positively correlated with latitude, implicating thermal stress during the early stages of development in the generation of some scute deformities. However, this relationship became non-significant when line (scute seam) abnormalities were excluded from the data, suggesting a different primary cause for the more severe scute deformities. Further research should continue to investigate the drivers of these deformities, as monitoring shifts in the frequency of scute deformities may provide relevant information for conservation and recovery of endangered turtles.
\end{abstract}

KEY WORDS: Population assignment $\cdot$ Spotted turtle $\cdot$ Clemmys guttata $\cdot$ Digital photographs · Carapace abnormalities $\cdot$ Genetic diversity $\cdot$ Latitude

\section{INTRODUCTION}

Effective management and conservation of wildlife populations require a sound knowledge of population demographics, which involves unique marking or identification of individuals within a population. Photographs provide a non-invasive tool for individual identification of some species, and are especially useful for species that are large and difficult to catch, easily stressed by handling, or are difficult to capture

\footnotetext{
${ }^{*}$ Corresponding author: christina.davy@ontario.ca
}

repeatedly. In some instances, photographic methods can reduce or eliminate the need for invasive marking methods that may cause discomfort, increase infection risk, alter animal behavior or performance, or become lost over time (Golay \& Durrer 1994, Nichols et al. 1998, Dugger et al. 2006, Reisser et al. 2008, Saraux et al. 2011, Walker et al. 2012).

Naturally occurring spot patterns have been used to successfully identify individuals of many taxa, including leopards Panthera pardus kotiya (Miththa-

() The authors 2021. Open Access under Creative Commons by Attribution Licence. Use, distribution and reproduction are unrestricted. Authors and original publication must be credited. 
pala et al. 1989, Kittle et al. 2017), sharks (Arzoumanian et al. 2005, Speed et al. 2007, Van Tienhoven et al. 2007, Holmberg et al. 2009), African penguins Spheniscus demersus (Sherley et al. 2010), and redspotted newts Notophthalmus viridescens (Gill 1978). Facial or cranial scale patterns can be used to identify individual sea turtles (e.g. Reisser et al. 2008, Schofield et al. 2008, Rees et al. 2013, Dunbar et al. 2014) and European adders Vipera berus (Bauwens et al. 2018), and variations in whisker spots on the nose can be used to distinguish individual polar bears Ursus maritimus (Anderson et al. 2007) and Australian sea lions Neophoca cinerea (Osterrieder et al. 2015). Natural body markings can even be used to identify individual Archey's frogs Leiopelma archeyi (Bradfield 2004).

If markings are either heritable or are driven by environmental variation, then some may also be population- or site-specific. Heritability and environmental effects of natural markings vary among taxa. Some aspects of spot patterns in giraffes Giraffa camelopardalis are partially heritable (Lee et al. 2018), while natural markings of Andean bears Tremarctos ornatus are not related to kinship (i.e. not heritable; Van Horn et al. 2015). Five different coat patterns were described in Eurasian lynx Lynx lynx, and their frequency of occurrence varied among areas into which the animals were re-introduced (Thüler 2002), suggesting that environmental drivers of markings varied among areas. If markings are reliably population- or site-specific (suggesting either heritability or environmental drivers of natural markings), then they could be used to assign confiscated, illegally collected individuals to their populations of origin. Live wild animals are confiscated by local, regional, and national authorities for a variety of reasons (e.g. injury, habitat destruction, poaching for the illegal pet trade), and sometimes these animals can be returned to the wild, after considering associated costs and benefits (IUCN 2000). For species at risk, reinforcement of populations might improve the longterm conservation potential (IUCN 2000); thus, if it can be determined that the preservation and welfare of existing wild populations of the species will not be harmed, the addition/return of individuals to an existing population of the same taxon could be a powerful conservation tool for these species.

In addition to aiding in identification, photographs may also contain information about wildlife health. Wildlife diseases with external clinical signs, such as sarcoptic mange, can be monitored in large felids and canids using camera traps (Oleaga et al. 2011, Ryser-Degiorgis 2013). Similar techniques were used to monitor dermal disease in wild bottlenose dolphins Tursiops truncatus (Thompson \& Hammond 1992). Photographs have also been used to monitor the behavior of disease vector species such as the European badger Meles meles, a potential source of bovine tuberculosis (Chen et al. 2019), and to explore interactions of wildlife with human activities, predators, and conspecifics. Images of marine mammals can be used to quantify wounds and scars likely caused by entanglement with fishing gear (Kiszka et al. 2009), vessel collisions (Kraus 1990, Calambokidis 1995, COSEWIC 2002, Langtimm et al. 2004), and/ or intra-/inter-specific social interactions (Heithaus 2001, Kiszka et al. 2009).

The Endangered spotted turtle Clemmys guttata is one of the smallest freshwater turtles in North America, and is distinguished by its smooth, black carapace covered with yellow-orange spots (Ernst \& Lovich 2009). Spotted turtles are threatened by road mortality, illegal collection for the pet trade, and habitat loss and degradation (van Dijk 2011, COSEWIC 2014, Howell \& Seigel 2019), threats that have placed approximately $61 \%$ of the 365 species of turtles recognized worldwide at risk of extinction over the past $500 \mathrm{yr}$ (Lovich et al. 2018). Conservation of turtles is challenging because populations recover extremely slowly from perturbations or catastrophic events. This is largely due to their slow life-history strategy, which includes slow growth rate, late age of maturity, low fecundity, and low survival rate of eggs and juveniles (Enneson \& Litzgus 2008, Keevil et al. 2018). Thus, the most effective strategy for conserving turtle populations may be the protection and maintenance of existing populations, rather than investing resources in recovery after declines have occurred (Congdon et al. 1994, Enneson \& Litzgus 2008).

Adult survivorship has the greatest proportional effect on population growth rate in spotted turtles (Enneson \& Litzgus 2008), so maximizing adult survival is essential to maintaining viable populations. Illegal collection of adult spotted turtles may not result in their death, but it mimics the effects of increased mortality by removing these individuals from a population. Returning confiscated spotted turtles to their population of origin can reverse the effects of their removal, but it is not always clear where these turtles should be released. Microsatellite markers can be used to assign confiscated turtles to known populations (Davy \& Murphy 2009), but genetic testing can be expensive and difficult to access. If spot patterns on spotted turtle carapaces were more similar within populations than among 
populations (i.e. among more closely related individuals than more distantly related individuals), perhaps these patterns could be used to assign confiscated individuals to their population of origin.

Photographs may also provide information useful for monitoring population viability or health. For example, scute abnormalities on turtle shells are easy to observe and quantify from photographs. Using photographs collected during routine field work, we were able to compare the occurrence of carapacial scute abnormalities among isolated populations of spotted turtles in Ontario, Canada. Turtles are excellent models for studying development instability because abnormalities can be easily seen in the form of shell malformations (Kazmaier \& Robel 2001, Davy \& Murphy 2009, Velo-Antón et al. 2011, Vas 2012, Farke \& Distler 2015, Moustakas-Verho \& Cherepanov 2015, Cherepanov 2016, Zimm et al. 2017). Scute abnormalities may result when developing eggs are subject to sub-optimal temperature, moisture, and/or salinity conditions (Lynn \& Ullrich 1950, Kazmaier \& Robel 2001, Telemeco et al. 2013); they have also been linked to loss of genetic diversity and latitude of the sampling site (Davy \& Murphy 2009, Velo-Antón et al. 2011).

In this study, we explored the potential for digital photographs to enable population-level assignments or act as proxies for population health in the Endangered spotted turtle. We annotated spot patterns on mature spotted turtles from 10 sites and then compared patterns among sites to investigate whether they could be used to assign individuals to their population of origin. We also quantified the frequency of carapacial scute abnormalities at these sites. These abnormalities are partially determined by genetic factors but may also provide a proxy for physiological stress experienced during egg development, so we explored their association with genetic diversity and latitude.

\section{MATERIALS AND METHODS}

\subsection{Sample collection}

We photographed spotted turtles during wading surveys conducted between April and October (2008-2018) at 10 sites (fens, bogs, and coastal marshes) across southern Ontario in the course of long-term mark-recapture studies. The sites were located in the Mixedwood Plains Ecozone, ranging in latitude from 42.317 to $45.494^{\circ} \mathrm{N}$. Pairwise distances between sites ranged from 3.5 to $638 \mathrm{~km}$. With the exception of BP1 and BP2, these sites represent isolated clusters of spotted turtles with little or no recent gene flow (Davy \& Murphy 2014), and we treated each sampling site as an independent 'population' in our analyses. Turtles were captured by hand and marked by shell notching (Cagle 1939). We took standard measurements, including carapace and plastron length, documented any shell abnormalities (e.g. missing, extra, or odd-shaped scutes; wavy lines between scutes), and took photographs of each turtle's carapace.

Hatchling spotted turtles emerge from the egg with only 1 spot per scute, and accumulate additional spots as they age (Ernst \& Lovich 2009). As adult spot patterns are unique to individuals, we hypothesized that spot patterns might also be more similar within a population than among populations. Juvenile spot patterns are quite consistent among individuals and could confound this analysis. To ensure no sub-adult individuals were included in our analysis, we only used photographs of mature turtles (turtles with a straight carapace length [SCL] $>97 \mathrm{~mm}$ ). We excluded photographs that were very dark or blurry, and photographs of turtles that had moss or algae growing on the carapace that might have obscured spots.

\subsection{Quantifying carapace spot patterns}

We used pattern-based interactive individual identification software ( ${ }^{3} \mathrm{~S}$ Spot) (Van Tienhoven et al. 2007, den Hartog \& Reijns 2014) to annotate the spot patterns of 126 individual spotted turtles from the 10 sampling sites. $\mathrm{I}^{3} \mathrm{~S}$ Spot is a free, computer-based photo-matching program that uses natural markings to identify individual study animals. We used the program to annotate spot pattern of each turtle and create a library of known individuals. Our hypothesis was that turtles could be assigned to population of origin based on their spot patterns, which predicts that spot patterns are more similar among individuals from the same population than among individuals from different populations. To test this prediction, we compared each individual's spot pattern with that of every other turtle in the database. For each comparison, the program lists pairwise numeric similarity scores in order of decreasing similarity, with lower scores representing closer matches (details in Van Tienhoven et al. 2007).

$\mathrm{I}^{3} \mathrm{~S}$ Spot requires the user to identify 3 fixed reference points on each photograph to correct for differences in viewing angle, rotation, and scaling among photographs. The location of these points should be 
consistent and clearly distinguishable in all photos, and the resulting triangle should cover most of the region of interest for identification (den Hartog \& Reijns 2014). Anterior and vertebral scutes were most consistently visible in our collection of photos, so we positioned reference points between the third and fourth marginal scutes posterior to the head, at the peripheral edge of the suture, and between the last 2 marginals at the posterior periphery of the carapace (Fig. 1). Within the annotation area, ellipses are fitted to each spot, and the spot pattern of each individual is established relative to these reference points in roughly the same $2 \mathrm{D}$ recognition space or coordinate system. Annotating too many spots may result in a computationally expensive comparison, while increasing the possibility of a false positive match between 2 fingerprints; annotating too few spots may not be distinctive enough (den Hartog \& Reijns 2014). To determine the scute sampling strategy that would maximize our chance of correctly assigning spotted turtles to their population of origin, we chose 4 annotation areas (A1 to A4, Fig. 1) and compared pairwise similarity scores for a sub-sample of 29 turtles from 4 sites (EO2, EO3, GH1, and HC). Annotation area A2 resulted in the largest difference between both median and mean scores for withinsite and among-site matches at each of the 4 sites (Fig. S1 \& Table S1 in the Supplement at www. int-res.com/articles/suppl/n045p159_supp.pdf); therefore, it was used to annotate spot patterns for all 126 turtles. To assess whether spot patterns could be used to identify the likely population of origin for spotted turtles, we calculated similarity scores for each pair of turtles and visualized these using a heat map.

\subsection{Carapacial scute abnormalities}

We also used photographs of spotted turtle shells to quantify carapacial scute abnormalities, and to explore associations between scute abnormalities and genetic diversity, and between scute abnormalities and latitude. We summarized carapace abnormalities from photographs of 206 spotted turtles; these included the 126 turtles described in Section 2.2 and additional individuals with SCL $<97 \mathrm{~mm}$ for which we had clear photographs. Each turtle received a binary score (yes/no) for the presence of carapacial scute abnormalities. These included extra or missing scutes, abnormally shaped scutes, split scutes, and any line (scute seam) abnormalities. Extra scutes were those that appeared to be embedded between 2 normally positioned scutes (Fig. 2A). Abnormally shaped scutes were positioned correctly, but appeared either very large, very small, asymmetric, or had a combination of unusual size and asymmetry (Fig. 2B). Split scutes were normally positioned scutes that were divided in 2, usually down the middle, either vertically or horizontally (Fig. 2D-F). Line abnormalities were cases where the separating line between scutes was wavy, zigzag, or otherwise uneven, even if the scutes themselves were of normal size and in the correct position (Fig. 2C,E).

We compared the frequency of scute abnormalities (proportion of sampled turtles that had some type of scute abnormality) at 9 study sites with previously published indices of genetic diversity (heterozygosity, allelic richness, and private allelic richness; Davy \& Murphy 2014); we did not have genetic data for site EO3. The relationship between each index of genetic diversity and the frequency of scute abnormalities was tested by calculating standard Pearson's correlation coefficients. We also tested the relationship between latitude of study site and frequency of scute abnormalities for all 10 sites by calculating a standard Pearson's correlation coefficient.

Line abnormalities were the most subjective of the abnormalities we documented, so we also excluded line abnormalities from the dataset and reran the analyses considering only misshapen, split, extra, or missing scutes as abnormalities. We conducted all statistical analyses in $\mathrm{R}$ version 3.5.1

(R Core Team 2018).
Fig. 1. We compared 4 annotation areas (A1-A4) to determine the scute sampling strategy that would maximize the chance of correctly assigning individual spotted turtles Clemmys guttata to their population of origin. All spots in shaded (gray) scutes were annotated using $\mathrm{I}^{3} \mathrm{~S}$ Spot. The same 3 reference points (black dots) and reference triangle were used for each annotation area

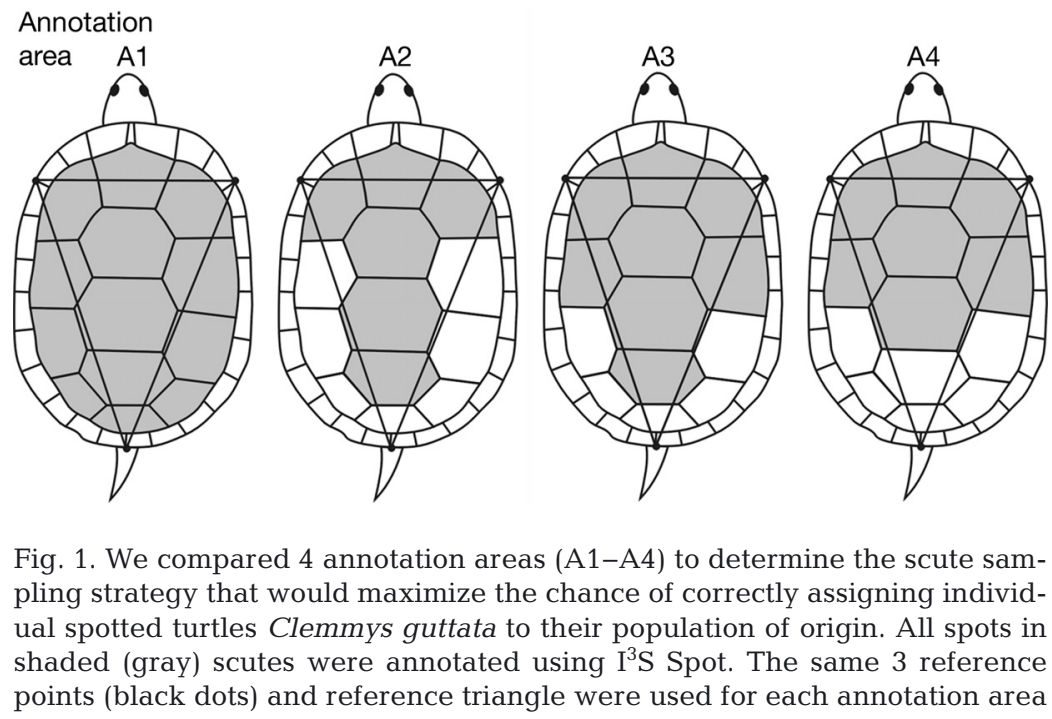




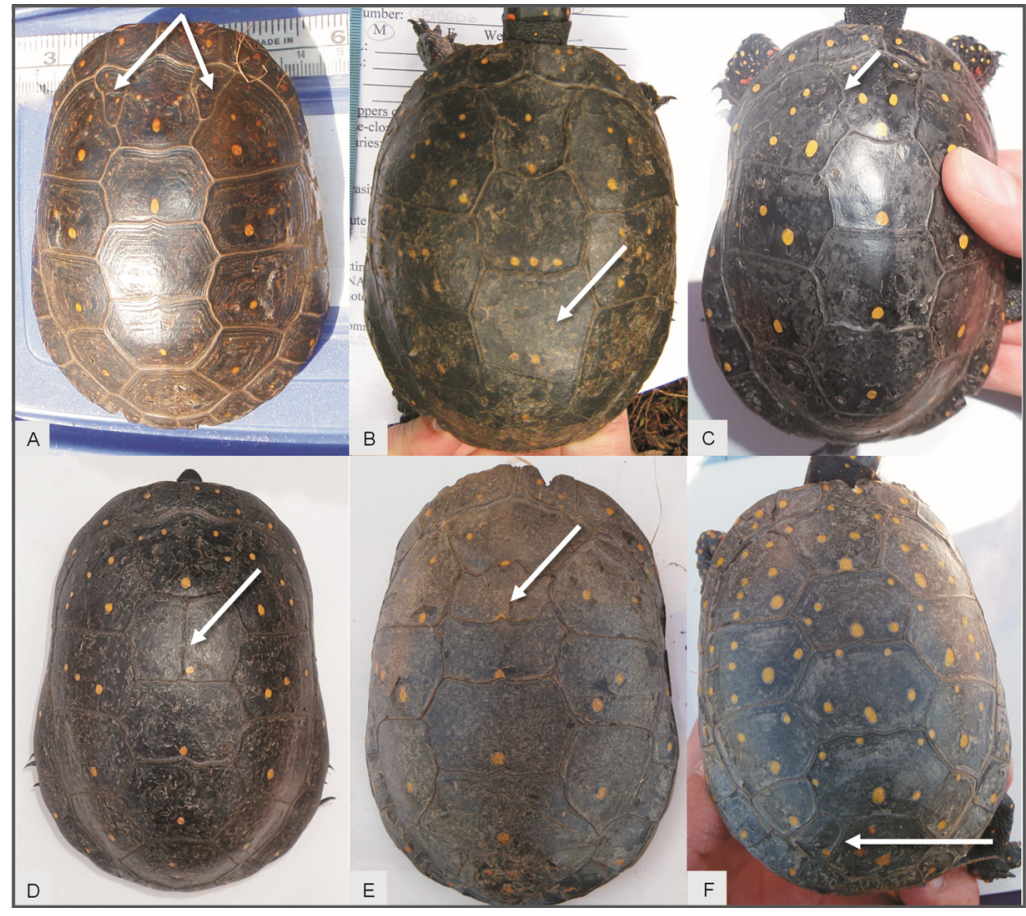

Fig. 2. Examples of carapace abnormalities in spotted turtles Clemmys guttata caught during annual wading surveys in southern Ontario, 2008-2018. Common carapace abnormalities observed (indicated by arrows) included: (A) extra scutes, (B) abnormally shaped (asymetrical) scutes (C,E) wavy or zigzag lines (seams) between scutes, and $(\mathrm{D}, \mathrm{E}, \mathrm{F})$ split vertebral and costal scutes

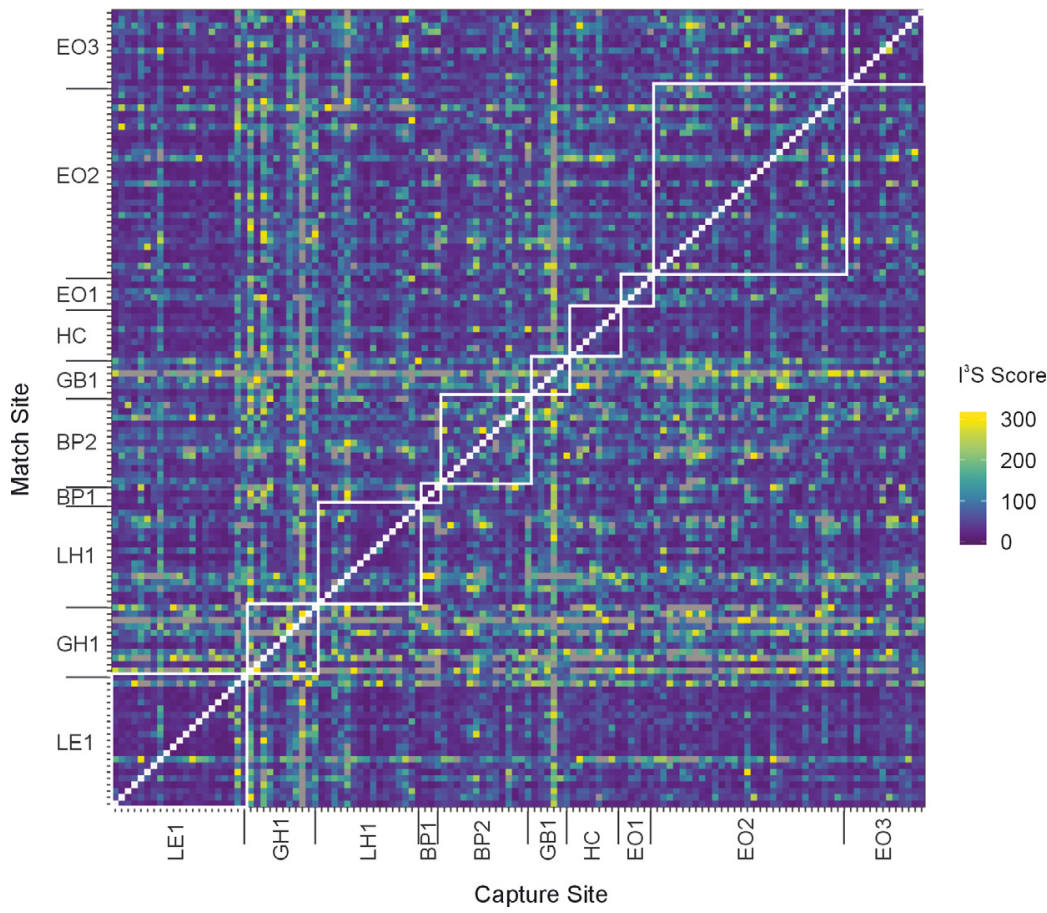

\section{RESULTS}

\subsection{Quantifying carapace spot patterns}

Pairwise $I^{3} S$ Spot similarity scores based on spot patterns overlapped substantially between within-site and among-site comparisons (Fig. 3), indicating that spot pattern similarity assessed with the methods we applied cannot be used to reliably assign a spotted turtle to its site (or population) of origin.

\subsection{Carapacial scute abnormalities}

Carapacial scute abnormalities were observed in $82 \%(170 / 206)$ of spotted turtles. Wavy or zigzag lines between scutes were the most common abnormality ( $\mathrm{n}=167)$. These were most often located between vertebrals 3 and $4(\mathrm{n}=114)$, between the first vertebral scute and the first costals $(\mathrm{n}=$ 94), and between vertebrals 2 and 3 $(\mathrm{n}=67)$. Fifty-one turtles had extra scutes, divided scutes, odd-shaped scutes, or some combination thereof, and 49 of those turtles also had uneven lines between scutes. Extra scutes were most common in this group $(\mathrm{n}=$ 33) and occurred mainly along the marginal scutes, and between the first vertebral and the first costals, but they never occurred on the same turtle. Divided scutes $(n=14)$ and odd-shaped

Fig. 3. Heat map of pairwise $\mathrm{I}^{3} \mathrm{~S}$ Spot similarity scores for spotted turtles Clemmys guttata $(\mathrm{n}=126)$ from 10 sampling sites in southern Ontario, Canada, ordered approximately from south-west to north-east, reflecting geographic proximity and genetic similarity among sites (Davy \& Murphy 2014). In each comparison, the first match in the output file was always the subject turtle's own photo (white squares in the diagonal). Low $1^{3} \mathrm{~S}$ scores (dark blue) indicate more similar spot patterns; high $1^{3} \mathrm{~S}$ scores (yellow) indicate more dissimilar spot patterns. White boxes indicate within-population comparisons for each sampled site 
scutes $(n=13)$ were less common; both occurred mainly along the vertebral scutes but rarely $(n=3)$ on the same turtle.

None of the genetic diversity indices we tested were correlated with the frequency of carapacial scute abnormalities in our dataset, regardless of whether line abnormalities were included in the dataset (Table 1). The frequency of carapacial scute abnormalities was positively correlated with latitude $\left(\mathrm{r}^{2}=0.69, \mathrm{p}=0.003\right.$; Table 1$)$. However, this correlation became non-significant when line abnormalities were excluded from the data (Table 1).

\section{DISCUSSION}

In this study, we used digital photos to annotate and compare carapace spot patterns among populations of spotted turtles, document and quantify carapace abnormalities, and investigate possible relationships of the frequency of abnormalities with genetic diversity and latitude. Regrettably, comparison of carapace spot patterns did not allow assignment of individuals to their population of origin. Spotted turtles at our study sites exhibited carapace abnormalities similar to those seen in other temperate freshwater turtle species. Frequency of these carapace abnormalities would not be a reliable proxy for genetic diversity, but the association with latitude when line abnormalities are included suggests that minor carapacial malformations may be a proxy for thermal stress experienced during development, when scutation develops.

Given a certain amount of phenotypic variability in a population, theory predicts that individuals within groups should be less variable (i.e. more similar in heritable phenotype) than individuals from different groups (Krause et al. 1996). In Mexico, intraspecific analyses of the Cortes geoduck Panopea globose shell shape suggested an adaptive or phenotypic response to environmental conditions at different sites (Leyva-Valencia et al. 2012). In California (USA), populations of topsmelt silverside Atherinops affinis from different regions were also morphologically distinct, suggesting the influence of environmental factors and local habitats (O'Reilly \& Horn 2004). We investigated phenotypic differences in spot patterns among disjunct populations of spotted turtles in the hope that they could be used to determine site of origin for recovered and/or rehabilitated individuals. Despite distances of $>10 \mathrm{~km}$ among our sites, spot patterning was not population- or site-specific. This result suggests that spot patterns are either not heritable or are not influenced by site-specific environmental factors, or that the analysis we performed failed to capture informative variation in these patterns. Although we have found that spot patterns and unique scute or scute seam abnormalities are useful for identifying individual spotted turtles, these were not informative for population-level assignment. For now, genetic testing remains the best option for assigning confiscated and/or rehabilitated Ontario spotted turtles to population of origin.

When developing embryos experience stressful conditions, such as heat or humidity near the boundaries of the tolerable range, mechanisms that regulate development can be challenged, resulting in increased phenotypic variance (Hoffmann \& Hercus 2000, Badyaev et al. 2005). Observed morphological variability may provide a valuable early indicator of genetic and/or environmental stress (Palmer \& Strobeck 1986, Parsons 1990), and detecting these can inform conservation of endangered populations (Leary \& Allendorf 1989). Scute abnormalities do not appear to affect fitness in freshwater turtles (Bujes \& Verrastro 2007, Davy \& Murphy 2009, Farke \& Distler 2015, Zimm et al. 2017). However, they may serve as indicators of developmental instability (Vas 2012), suboptimal thermal or hydric conditions during development (Zangerl \& Johnson 1957, Moustakas-

Table 1. Associations (Pearson's correlation coefficient) between the frequency of carapacial scute abnormalities (where 'Line' refers to the scute seam) observed in spotted turtles Clemmys guttata at 10 sites in southern Ontario, Canada, and site latitude (as a proxy for thermal exposure while turtles are developing), as well as 3 measures of neutral genetic diversity, inferred previously with data from 11 microsatellite loci (Davy \& Murphy 2014)

\begin{tabular}{|c|c|c|c|c|c|c|c|c|}
\hline & \multicolumn{4}{|c|}{ Line abnormalities included } & \multicolumn{4}{|c|}{ Line abnormalities excluded } \\
\hline & $t$ & $\mathrm{df}$ & $\mathrm{r}^{2}$ & $\mathrm{p}$ & $t$ & $\mathrm{df}$ & $\mathrm{r}^{2}$ & $\mathrm{p}$ \\
\hline Observed heterozygosity & -0.126 & 7 & 0.0023 & 0.9032 & 1.5485 & 7 & 0.2551 & 0.1654 \\
\hline Allelic richness & -1.302 & 7 & 0.195 & 0.2341 & 0.7906 & 7 & 0.082 & 0.4551 \\
\hline Private allelic richness & -0.093 & 7 & 0.0012 & 0.9284 & 0.2606 & 7 & 0.0096 & 0.8019 \\
\hline Latitude & 4.2228 & 8 & 0.6903 & 0.0029 & -0.225 & 8 & 0.0063 & 0.8276 \\
\hline
\end{tabular}


Verho \& Cherepanov 2015, Cherepanov 2016, Zimm et al. 2017), or potential exposure to environmental contaminants (Bishop et al. 1998, Bell et al. 2006). Thus, patterns in the occurrence of scute abnormalities may be worthy of further investigation, especially where endangered species are concerned.

We observed carapace abnormalities in 67-100\% of spotted turtles from 10 sites, which is similar to the frequency of scute abnormalities (63-75\%) reported in some studies of the European pond turtle Emys orbicularis (Fernández \& Cordero-Rivera 2004, VeloAntón et al. 2011). However, in most other species, the reported frequency of scute abnormalities (3$44 \%$ ) is lower (MacCulloch 1981, Bishop et al. 1998, Kazmaier \& Robel 2001, Bujes \& Verrastro 2007, Davy \& Murphy 2009, Vas 2012, Kosik et al. 2013, McKnight \& Ligon 2014, Farke \& Distler 2015, Loehr 2016, Saçdanaku \& Haxhiu 2016, Zimm et al. 2017, Lada \& Boldyreva 2018). Scute abnormalities in our turtles were biased towards the vertebral scutes, similar to findings in European pond turtles (Fernández \& Cordero-Rivera 2004, Kosik et al. 2013, Saçdanaku \& Haxhiu 2016) and sea turtles (Zimm et al. 2017). Extra scutes and divided scutes like those we observed were also reported in co-occurring populations of snapping turtles Chelydra serpentina (Bishop et al. 1998) and painted turtles Chrysemys picta (MacCulloch 1981, Davy \& Murphy 2009).

Some studies have suggested an association between decreasing genetic diversity and the incidence of scute abnormalities (Velo-Antón et al. 2011, Kosik et al. 2013). However, genetic diversity estimated from microsatellite markers did not explain the variation in frequency of abnormalities seen in spotted turtles at our study sites. The only association we found between scute abnormalities and characteristics of the sampled population was between frequency of carapace abnormalities and latitude of the sampling sites, although this association became nonsignificant when line abnormalities were not included in the data. Potential links between latitude and carapace malformation are consistent with previous studies of painted turtles (Davy \& Murphy 2009) and Iberian populations of European pond turtles (Cordero-Rivera et al. 2008, Velo-Antón et al. 2011).

Protection, maintenance, and enhancement of existing populations are essential for long-term conservation and recovery of endangered turtle species (Congdon et al. 1994, Enneson \& Litzgus 2008). Unfortunately, spot pattern similarity did not prove useful for assigning confiscated individuals back to their populations of origin (at least in the case of Ontario spotted turtles), leaving genetic assignment tests as the only available option, and even these are imperfect (Davy \& Murphy 2014). Nevertheless, the association between carapace abnormalities and latitude implicates environmental stressors in the development of scute abnormalities, suggesting that longterm monitoring of carapace abnormalities could identify long-term shifts in stressors experienced by developing turtle embryos. Given the limited ability of turtle populations to recover after population declines (Brooks et al. 1991, Congdon et al. 1993, Heppell 1998, Enneson \& Litzgus 2008, Keevil et al. 2018), monitoring the incidence of scute abnormalities among age-classes could provide a valuable, cost-effective 'early-warning system' for shifts in the severity of developmental stressors.

Acknowledgements. We thank C. Brdar, S. Coombes, M. Gibson, A. Leifso, J. Paterson, V. Von Zuben, A. Whitear, K. T. Yagi, and A. R. Yagi for field assistance with turtle surveys included here. Megan Rasmussen shared further photographs of spotted turtles. This research was supported by the Government of Ontario.

\section{LITERATURE CITED}

Anderson C, Roth J, Waterman J (2007) Can whisker spot patterns be used to identify individual polar bears? J Zool (Lond) 273:333-339

Arzoumanian Z, Holmberg J, Norman B (2005) An astronomical pattern-matching algorithm for computer-aided identification of whale sharks Rhincodon typus. J Appl Ecol 42:999-1011

Badyaev AV, Foresman KR, Young RL (2005) Evolution of morphological integration: developmental accommodation of stress-induced variation. Am Nat 166:382-395

* Bauwens D, Claus K, Mergeay J (2018) Genotyping validates photo-identification by the head scale pattern in a large population of the European adder (Vipera berus). Ecol Evol 8:2985-2992

* Bell B, Spotila JR, Congdon J (2006) High incidence of deformity in aquatic turtles in the John Heinz National Wildlife Refuge. Environ Pollut 142:457-465

* Bishop CA, Ng P, Pettit K, Kennedy S, Stegeman J, Norstrom R, Brooks R (1998) Environmental contamination and development abnormalities in eggs and hatchlings of the common snapping turtle (Chelydra serpentina serpentina) from the Great Lakes-St Lawrence River basin (1989-91). Environ Pollut 101:143-156

Bradfield KS (2004) Photographic identification of individual Archey's frogs, Leiopelma archeyi, from natural markings. DOC Science International Series 191. Department of Conservation, Wellington. https://www.doc.govt.nz/ documents/science-and-technical/dsis191.pdf

* Brooks RJ, Brown GP, Galbraith DA (1991) Effects of a sudden increase in natural mortality of adults on a population of the common snapping turtle (Chelydra serpentina). Can J Zool 69:1314-1320

Bujes CS, Verrastro L (2007) Supernumerary epidermal shields and carapace variation in Orbigny's slider turtles, Trachemys dorbigni (Testudines, Emydidae). Rev Bras Zool 24:666-672 
Cagle F (1939) A system of marking turtles for future identification. Copeia 1939:170-173

Calambokidis I (1995) Blue whales off California. Whalewatcher 29:3-7

* Chen R, Little R, Mihaylova L, Delahay R, Cox R (2019) Wildlife surveillance using deep learning methods. Ecol Evol 9:9453-9466

* Cherepanov G (2016) Nature of the turtle shell: morphogenetic causes of bone variability and its evolutionary implication. Paleontol J 50:1641-1648

Congdon JD, Dunham AE, van Loben Sels RC (1993) Delayed sexual maturity and demographics of Blanding's turtles (Emydoidea blandingii): implications for conservation and management of long-lived organisms. Conserv Biol 7:826-833

Congdon JD, Dunham AE, van Loben Sels RCV (1994) Demographics of common snapping turtles (Chelydra serpentina): implications for conservation and management of long-lived organisms. Am Zool 34:397-408

Cordero-Rivera A, Ayres C, Velo-Anton G (2008) High prevalence of accessory scutes and anomalies in Iberian populations of Emys orbicularis. Rev Esp Herpetol 22:5-14

COSEWIC (Committee on the Status of Endangered Wildlife in Canada) (2002) COSEWIC assessment and update status report on the blue whale Balaenoptera musculus in Canada. Committee on the Status of Endangered Wildlife in Canada, Ottawa

COSEWIC (2014) Assessment and status report on the spotted turtle Clemmys guttata in Canada. Committee on the Status of Endangered Wildlife in Canada, Ottawa

Davy CM, Murphy RW (2009) Explaining patterns of deformity in freshwater turtles using MacCulloch's hypothesis. Can J Zool 87:433-439

Davy CM, Murphy RW (2014) Conservation genetics of the endangered spotted turtle (Clemmys guttata) illustrate the risks of 'bottleneck tests'. Can J Zool 92:149-162

den Hartog J, Reijns R (2014) I'S Spot Manual: Interactive Individual Identification System version 4.0.2. 1-43. https:// reijns.com/wp-content/uploads/2020/01/I3S-Spot.pdf

Dugger KM, Ballard G, Ainley DG, Barton KJ (2006) Effects of flipper bands on foraging behavior and survival of Adélie penguins (Pygoscelis adeliae). Auk 123:858-869

Dunbar S, Ito HE, Bahjri K, Dehom S, Salinas L (2014) Recognition of juvenile hawksbills Eretmochelys imbricata through face scale digitization and automated searching. Endang Species Res 26:137-146

Enneson JJ, Litzgus JD (2008) Using long-term data and a stage-classified matrix to assess conservation strategies for an endangered turtle (Clemmys guttata). Biol Conserv 141:1560-1568

Ernst CH, Lovich JE (2009) Turtles of the United States and Canada, $2^{\text {nd }}$ edn. The Johns Hopkins University Press, Baltimore, MD

Farke CM, Distler C (2015) Ontogeny and abnormalities of the tortoise carapace: a computer tomography and dissection study. Salamandra 51:231-244

Fernández CA, Cordero-Rivera A (2004) Asymmetries and accessory scutes in Emys orbicularis from northwest Spain. Biologia (Bratisl) 59:85-88

* Gill DE (1978) The metapopulation ecology of the redspotted newt, Notophthalmus viridescens. Ecol Monogr 48:145-166

Golay N, Durrer H (1994) Inflammation due to toe-clipping in natterjack toads (Bufo calamita). Amphib-Reptilia 15: 81-83
Heithaus M (2001) Shark attacks on bottlenose dolphins (Tursiops aduncus) in Shark Bay, Western Australia: attack rate, bite scar frequencies, and attack seasonality. Mar Mamm Sci 17:526-539

Heppell SS (1998) Application of life-history theory and population model analysis to turtle conservation. Copeia 1998:367-375

* Hoffmann AA, Hercus MJ (2000) Environmental stress as an evolutionary force. Bioscience 50:217-226

*Holmberg J, Norman B, Arzoumanian Z (2009) Estimating population size, structure, and residency time for whale sharks Rhincodon typus through collaborative photoidentification. Endang Species Res 7:39-53

Howell HJ, Seigel RA (2019) The effects of road mortality on small, isolated turtle populations. J Herpetol 53:39-46

IUCN (2000) IUCN guidelines for the placement of confiscated animals. IUCN, Gland

Kazmaier RT, Robel RJ (2001) Scute anomalies of ornate box turtles in Kansas. Trans Kans Acad Sci 104:178-182

Keevil MG, Brooks RJ, Litzgus JD (2018) Post-catastrophe patterns of abundance and survival reveal no evidence of population recovery in a long-lived animal. Ecosphere 9:e02396

Kiszka J, Pelourdeau D, Ridoux V (2009) Body scars and dorsal fin disfigurements as indicators of interaction between small cetaceans and fisheries around the Mozambique Channel Island of Mayotte. West Indian Ocean J Mar Sci 7:185-193

Kittle AM, Watson AC, Fernando TSP (2017) The ecology and behaviour of a protected area Sri Lankan leopard (Panthera pardus kotiya) population. Trop Ecol 58: 71-86

Kosik E, Wójcik M, Beeger S, Rozempolska-Rucińska I (2013) Carapace anomalies of pond turtles (Emys orbicularis) from the Poleski National Park, from the hatch of 2008. Ann Univ Mariae Curie-Sklodowska 68:34-42

Kraus S (1990) Rates and potential causes of mortality in North American right whales (Eubalaena glacialis). Mar Mamm Sci 6:278-291

K Krause J, Godin JG, Brown D (1996) Phenotypic variability within and between fish shoals. Ecology 77:1586-1591

*Lada G, Boldyreva M (2018) Pholidosis abnormalities and injuries in the European pond turtle (Emys orbicularis) in the conditions of the Khopersky Nature Reserve. KnE Life Sci 4:87-91

KLangtimm CA, Beck CA, Edwards HH, Fick-Child KJ, Ackerman BB, Barton SL, Hartley WC (2004) Survival estimates for Florida manatees from the photo-identification of individuals. Mar Mamm Sci 20:438-463

* Leary RF, Allendorf FW (1989) Fluctuating asymmetry as an indicator of stress: implications for conservation biology. Trends Ecol Evol 4:214-217

* Lee DE, Cavener DR, Bond ML (2018) Seeing spots: quantifying mother-offspring similarity and assessing fitness consequences of coat pattern traits in a wild population of giraffes (Giraffa camelopardalis). PeerJ 6:e5690

KLeyva-Valencia I, Álvarez-Castañeda ST, Lluch-Cota DB, González-Peláez S and others (2012) Shell shape differences between two Panopea species and phenotypic variation among $P$. globosa at different sites using two geometric morphometrics approaches. Malacologia 55: $1-13$

KLehr VJ (2016) Wide variation in carapacial scute patterns in a natural population of speckled tortoises, Homopus signatus. Afr J Herpetol 65:47-54 
Lovich JE, Ennen JR, Agha M, Gibbons JW (2018) Where have all the turtles gone, and why does it matter? Bioscience 68:771-781

Lynn WG, Ullrich M (1950) Experimental production of shell abnormalities in turtles. Copeia 1950:253-262

MacCulloch RD (1981) Variation in the shell of Chrysemys picta belli from southern Saskatchewan. J Herpetol 15: 181-185

McKnight DT, Ligon DB (2014) Shell and pattern abnormalities in a population of western chicken turtles (Deirochelys reticularia miaria). Herpetol Notes 7:89-91

Miththapala S, Seidensticker J, Phillips L, Fernando S, Smallwood J (1989) Identification of individual leopards (Panthera pardus kotiya) using spot pattern variation. J Zool (Lond) 218:527-536

Moustakas-Verho JE, Cherepanov GO (2015) The integumental appendages of the turtle shell: an evo-devo perspective. J Exp Zool B Mol Dev Evol 324:221-229

Nichols WJ, Seminoff JA, Resendiz A (1998) Plastic 'rototags' may be linked to sea turtle bycatch. Mar Turtle Newsl 79:20-21

* O'Reilly K, Horn M (2004) Phenotypic variation among populations of Atherinops affinis (Atherinopsidae) with insights from a geometric morphometric analysis. J Fish Biol 64:1117-1135

* Oleaga Á, Casais R, Balseiro A, Espí A, Llaneza L, Hartasánchez A, Gortázar C (2011) New techniques for an old disease: sarcoptic mange in the Iberian wolf. Vet Parasitol 181:255-266

Osterrieder SK, Kent CS, Anderson CJ, Parnum IM, Robinson RW (2015) Whisker spot patterns: a noninvasive method of individual identification of Australian sea lions (Neophoca cinerea). J Mammal 96:988-997

Palmer AR, Strobeck C (1986) Fluctuating asymmetry: measurement, analysis, patterns. Annu Rev Ecol Syst 17: 391-421

* Parsons PA (1990) Fluctuating asymmetry: an epigenetic measure of stress. Biol Rev Camb Philos Soc 65:131-145

R Core Team (2018) R: a language and environment for statistical computing. R Foundation for Statistical Computing, Vienna

Rees AF, Al Hafez AA, Papathanasopoulou N (2013) Utility of sea turtle photo ID techniques: the example of a male hawksbill in Kuwait. Indian Ocean Turtle Newsl 17:23-25

Reisser J, Proietti M, Kinas P, Sazima I (2008) Photographic identification of sea turtles: method description and validation, with an estimation of tag loss. Endang Species Res 5:73-82

Ryser-Degiorgis MP (2013) Wildlife health investigations: needs, challenges and recommendations. BMC Vet Res 9:223

Saçdanaku E, Haxhiu I (2016) Accessory scutes and asymmetries in European pond turtle, Emys orbicularis (Lin-

Editorial responsibility: Mark Hamann,

Townsville, Queensland, Australia

Reviewed by: 3 anonymous referees naeus, 1758) and Balkan terrapin, Mauremys rivulata (Valenciennes, 1833) from Vlora Bay, western Albania. Int J Fauna Biol Stud 3:127-132

Saraux C, Le Bohec C, Durant JM, Viblanc VA and others (2011) Reliability of flipper-banded penguins as indicators of climate change. Nature 469:203-206

* Schofield G, Katselidis KA, Dimopoulos P, Pantis JD (2008) Investigating the viability of photo-identification as an objective tool to study endangered sea turtle populations. J Exp Mar Biol Ecol 360:103-108

Sherley RB, Burghardt T, Barham PJ, Campbell N, Cuthill IC (2010) Spotting the difference: towards fullyautomated population monitoring of African penguins Spheniscus demersus. Endang Species Res 11:101-111

Speed CW, Meekan MG, Bradshaw CJA (2007) Spot the match - wildlife photo-identification using information theory. Front Zool 4:2

* Telemeco RS, Warner DA, Reida MK, Janzen FJ (2013) Extreme developmental temperatures result in morphological abnormalities in painted turtles (Chrysemys picta): a climate change perspective. Integr Zool 8:197-208

Thompson PM, Hammond PS (1992) Use of photography to monitor dermal disease in wild bottlenose dolphins (Tursiops truncatus). Ambio 21:135-137

Thüler K (2002) Spatial and temporal distribution of coat patterns of Eurasian lynx (Lynx lynx) in two re-introduced populations in Switzerland (KORA Rep 13). Diploma thesis, University of Bern

*van Dijk P (2011) Spotted turtle. Clemmys guttata. The IUCN Red List of Threatened Species 2011: e.T4968A97411228. https://dx.doi.org/10.2305/IUCN.UK.20111.RLTS.T4968A11103766.en

*Van Horn RC, Zug B, Appleton RD, Velez-Liendo X, Paisley $\mathrm{S}$, LaCombe C (2015) Photos provide information on age, but not kinship, of Andean bear. PeerJ 3:e1042

*Van Tienhoven A, Den Hartog J, Reijns R, Peddemors V (2007) A computer-aided program for pattern-matching of natural marks on the spotted raggedtooth shark Carcharias taurus. J Appl Ecol 44:273-280

*Vas R (2012) Carapacial scute anomalies of star tortoises (Geochelone elegans) in Western India. TAPROBANICA J Asian Biodivers 4:105-107

*Velo-Antón G, Becker CG, Cordero-Rivera A (2011) Turtle carapace anomalies: the roles of genetic diversity and environment. PLOS ONE 6:e18714

*Walker KA, Trites AW, Haulena M, Weary DM (2012) A review of the effects of different marking and tagging techniques on marine mammals. Wildl Res 39:15-30

Zangerl R, Johnson RG (1957) The nature of shield abnormalities in the turtle shell. Fieldiana Geol 10:341-362

Kimm R, Bentley BP, Wyneken J, Moustakas-Verho JE (2017) Environmental causation of turtle scute anomalies in ovo and in silico. Integr Comp Biol 57:1303-1311

Submitted: September 29, 2020

Accepted: February 16, 2021

Proofs received from author(s): June 2, 2021 